\title{
Effect of Donor Age and Sex on the Outcome of Liver Transplantation
}

\author{
Ignazio Roberto Marino, ${ }^{1,2}$ Howard R. Doyle, ${ }^{1,2}$ Luca Aldrighetti, ${ }^{1}$ CAtaldo Doria, ${ }^{1}$ John McMichael, ${ }^{1}$ \\ Timothy Gayowski, ${ }^{1,2}$ John J. Fung, ${ }^{1}$ Andreas G. Tzakis, ${ }^{1,3}$ and Thomas E. StarzL ${ }^{1,2}$
}

\begin{abstract}
We correlated donor and recipient factors with graft outcome in 436 adult patients who underwent 462 liver transplants. Donor variables analyzed were age, gender, ABO blood group, cause of death, length of stay in the intensive care unit, use of pressors or pitressin, need for cardiopulmonary resuscitation, terminal serum transaminases, and ischemia time. Recipient variables analyzed were age, gender, primary diagnosis, history of previous liver transplant, ABO blood group, cytotoxic antibody crossmatch, United Network for Organ Sharing (UNOS) status, and waiting time (except for the cross-match results, they were all known at the time of the operation). The endpoint of the analysis was graft failure, defined as patient death or retransplantation. Using multivariate analysis, graft failure was significantly associated with donor age, donor gender, previous liver transplantation, and UNOS 4 status of the recipient. The effect of donor age became evident only when they were older than 45 years. Livers from female donors yielded significantly poorer results, with 2-year graft survival of female to male $55 \%(95 \% \mathrm{CI}, 45 \%$ to $67 \%)$; female to female, $64 \%(95 \% \mathrm{CI}, 54 \%$ to $77 \%)$; male to male, $72 \%(95 \%$ CI, $66 \%$ to $78 \%)$; and male to female, $78 \%(95 \%$ CI, $70 \%$ to $88 \%$ ). The only donors identified as questionable for liver procurement were old ( $\geq 60$ years) women in whom the adverse age and gender factors were at least additive. However, rather than discard even these livers, in the face of an organ shortage crisis, their individualized use is suggested with case reporting in a special category. (HEPATOLOGY 1995;22:1754-1762.)
\end{abstract}

As of January 4, 1995, 37,751 transplant candidates were registered on the national waiting list operated by the United Network for Organ Sharing (UNOS), the agency that coordinates organ allocation in the United States. This was a $391 \%$ increase from the 9,632 wait-

Abbreviation: UNOS, United Network for Organ Sharing.

From the ${ }^{1}$ Pittsburgh Transplantation Institute, University of Pittsburgh Medical Center, the ${ }^{2}$ Veterans Administration Medical Center, Pittsburgh, PA and ${ }^{3}$ the Division of Transplantation, University of Miami, Miami, FL.

Received April 20, 1995; accepted August 28, 1995.

Aided by research grants from the Veterans Administration and project grant no. DK29961 from the National Institutes of Health, Bethesda, MD.

Address reprint requests to: Ignazio Roberto Marino, MD, Pittsburgh Transplantation Institute, Department of Surgery, University of Pittsburgh, 4W Falk Clinic, 3601 Fifth Ave, Pittsburgh, PA 15213.

Copyright (c) 1995 by the American Association for the Study of Liver Diseases.

$0270-9139 / 95 / 2206-0021 \$ 3.00 / 0$ ing in December 1986. Of the 37,751 in $1995,4,039$ were liver candidates, up from 449 in 1987 (a 900\% increase). The supply of all organ donors had undergone a marginal increase between 1988 and 1990 (from 4,085 to 4,514 ), but has remained relatively stable since then: 4,531 in $1991,4,521$ in $1992,4,849$ in 1993 , and 4,891 in 1994.

The limited supply of organ donors has increasingly influenced the selection of candidates for liver transplantation, and is used at some institutions to justify restricting the availability of the procedure. ${ }^{1}$ Although the exact magnitude of the organ deficit is not yet known, ${ }^{2,3}$ the obvious gap between supply and need has stimulated the development of bioartificial liver assist devices, ${ }^{4}$ utilization of living related liver donors,${ }^{5,6}$ use of non-heart beating donors, ${ }^{7-9}$ and xenotransplantation. ${ }^{10} \mathrm{~A}$ more immediate impact on organ shortage already has come from the widespread use of livers from "marginal donors," as first documented by Makowka et $\mathrm{al}^{11}$ and Pruim et al. ${ }^{12}$

The definition of a marginal donor has varied in different reports, and recently has included obesity. ${ }^{13,14}$ Two potential risk factors - age and gender-are relevant with all donors, no matter what the other circumstances of death. Although it has long been thought that the liver is less affected than other organs by senescence, ${ }^{15,16}$ poor experience with older donors in the original Denver series (including two who were 73 years of age) resulted in an upper donor age limitation of 45 years. ${ }^{17}$ The demonstration that satisfactory livers could be obtained from donors well into the seventh decade of life ${ }^{18,19}$ or beyond ${ }^{20}$ was followed by a flurry of confirmatory reports, ${ }^{13,14,21,22}$ countered by descriptions of degraded results using geriatric livers. ${ }^{23-26}$

Less has been written about the effect of donor sex on outcome after liver transplantation, although there is an extensive literature, recently summarized by Neugarten and Silbiger, ${ }^{27}$ showing poorer results with kidney allografts from female donors. We have reported similar findings with female livers in adults ${ }^{28,29}$ but not in children. ${ }^{30}$ The gender effect has been disputed by Stratta et al. ${ }^{31}$

In the current study, we have examined with univariate and multivariate analyses the effect on outcome of donor age and sex, singly and together, in a consecutive series of liver recipients, taking into account an array 
of other risk factors. A clear influence of both donor age and gender on outcome was identifiable.

\section{PATIENTS AND METHODS}

From January 1, 1992 to June 30, 1993, 436 consecutive adult patients received 479 liver transplants at the University of Pittsburgh Medical Center and the Veterans Administration Medical Center, Pittsburgh, PA. The livers in 17 were part of multivisceral transplants that included intestine. These cases were excluded, leaving 419 recipients of 462 allografts who were entered for analysis. The information was obtained from the clinical database maintained by the Pittsburgh Transplantation Institute, and a review of the donor charts that are kept on file at the Center for Organ Recovery and Education (Western Pennsylvania Organ Procurement Organization) Pittsburgh, PA.

All grafts were flushed with the University of Wisconsin solution. No attempt was made to transplant older livers into older recipients, or vice versa. ABO compatibility, size match, and medical urgency (UNOS status, see later discussion), were the only criteria used in recipient selection. All recipients were treated with the same immunosuppressive protocol, based on tacrolimus (Prograf, formerly FK506, Fujisawa USA, Inc., Deerfield, IL) and prednisone, augmented by azathioprine and antilymphocyte globulin in a small minority of cases. Intravenous prostaglandin $\mathrm{E}_{1}$ was routinely given perioperatively. ${ }^{32}$

\section{Variables Studied}

Donors. Age, gender, ABO blood group, cause of death, length of stay in the intensive care unit, need for pressors or pitressin, need for cardiopulmonary resuscitation, terminal serum transaminases (alanine transaminase and aspartate transaminase), and ischemia time were studied.

Recipients. Recipient variables included age, gender, diagnosis, history of previous liver transplant, ABO blood group, UNOS status, waiting time, results of the cytotoxic crossmatch, patient and graft survival times, and cause of graft failure. The indications for orthotopic liver transplantation were collapsed into seven diagnostic categories (Table 1). In the case of a retransplantation, the diagnosis was the cause of the preceding graft failure.

TABLe 1. Diagnostic Categories

\begin{tabular}{|c|c|}
\hline Category & Diagnoses \\
\hline Posthepatitic & $\begin{array}{l}\text { Hepatitis } B \text {, hepatitis } C \text {, and non- } A \text {, non- } B \text {, } \\
\text { non-C }\end{array}$ \\
\hline Cholestatic & $\begin{array}{l}\text { PBC, PSC, cystic fibrosis, secondary biliary } \\
\text { cirrhosis, biliary atresia, etc. }\end{array}$ \\
\hline Cryptogenic & All other diagnoses excluded \\
\hline Alcoholic & Ethanol-induced cirrhosis \\
\hline Malignancy & Primary or secondary \\
\hline Ischemic injury & $\begin{array}{l}\text { Primary nonfunction and late failures due } \\
\text { to harvest injury }\end{array}$ \\
\hline Other* & $\begin{array}{l}\text { Budd-Chiari syndrome, sarcoidosis, } \\
\text { fulminant failure, etc. }\end{array}$ \\
\hline
\end{tabular}

Abbreviations: PBC, primary biliary cirrhosis; PSC, primary sclerosing cholangitis.

* The category "Other" encompasses diagnoses with 10 or fewer observations.

\section{Definitions}

Graft Failure. Patient death or retransplantation at any time during follow-up was considered a graft failure. A separate analysis also was made of "early failures" within 90 days of transplantation. Primary nonfunction, a subcategory of early failure, referred to a graft that had such poor initial function that retransplantation or death occurred within 2 weeks. Failures attributable to technical errors were not considered as primary nonfunction.

Severe Ischemic Injury. Severe ischemic injury referred to damage of the allograft, either before revascularization or afterward, that did not have a demonstrable immunologic cause. Causes of the damage included hemodynamic or toxic insults in the donor; injury during harvesting, transport, or on the back table; and recipient cardiovascular instability after revascularization. For the purposes of analysis, organs lost to primary nonfunction or ischemic injury are grouped together.

Medical Urgency. Medical urgency was rated as follows: UNOS 1: patient stable at home; UNOS 2: waiting at home, but requiring medical support; UNOS 3: unstable, in need of continuous hospitalization; UNOS 4: requirement of lifesupport systems.

Waiting Time. Waiting time was the number of days between acceptance on the UNOS waiting list and the day of the transplantation.

Ischemia Time. Ischemia time was the time elapsed from aortic cross-clamping in the donor to portal or arterial revascularization in the recipient.

Need for Pressors. Dopamine infusion $>10 \mu \mathrm{g} / \mathrm{kg} / \mathrm{min}$, or need for a continuous infusion, at any dose level, of epinephrine or norepinephrine was classified as a need for pressors.

\section{Statistical Analysis}

Univariate. Continuous variables are presented as the mean \pm SEM, and categorical variables as rates. For continuous variables, two-tailed $t$-tests determined whether there was a difference between groups. Pearson's $\chi^{2}$ for $2 \times \mathrm{k}$ tables tested for association in categorical variables. If an association was found in variables containing more than two categories, a Tukey-Kramer multiple comparisons procedure on $\mathrm{k}$ groups with Bernoulli responses ${ }^{33}$ was used to identify the individual categories that were significantly different. The Mantel-Haenzel test was used to control for confounding variables. The level of significance for all tests was set at .05.

Multivariate. Variables found with univariate analyses to be associated with outcome, or whose association was of borderline significance, were then used in a stepwise logistic regression analysis to identify the variables that are independent predictors of outcome. In the case of categorical variables, preliminary univariate logistic regression models were fit to determine if subcategories should be grouped together. Models were fit using both forward inclusion and backward elimination, with a likelihood ratio test to determine which variables were to remain in the model after each iteration. A significance level of .1 was used in the stepwise procedure.

To further explore the relationship between donor age and graft outcome, a generalized additive model ${ }^{34}$ was fit, using the four variables identified during the stepwise logistic regression analysis (see Results). Three of these variables were categorical and were coded as either 0 (absent) or 1 (present). Donor age was entered into the model as a continuous measure, using a local regression procedure. ${ }^{35}$ Once the functional relation between donor age and the probability of graft failure was determined, it was possible to calculate pointwise stan- 
dard errors on the predicted probabilities by fitting a generalized linear model, ${ }^{36}$ substituting a regression spline for the smooth age term (see Results). Pointwise confidence intervals were calculated using a Bonferroni adjustment.

Survival. The Kaplan-Meier method was used, with differences between curves determined by means of the log rank test.

The univariate analyses and stepwise logistic regression procedure were performed using SPSS (SPSS Inc., Chicago, IL). All other procedures were performed using S-Plus (Stat Sci, Seattle, WA).

\section{RESULTS}

\section{Univariate Analysis}

The 419 recipients of 462 livers were followed for 1.12 to 2.6 years. Of the 462 livers, 452 were transplanted alone, and the other 10 were combinations with a kidney $(n=4)$, bone marrow $(n=4)$, heart $(n=1)$, and pancreatic islets $(n=1)$. The only $A B O$ mismatch, $\mathrm{A} \rightarrow \mathrm{O}$, was successful. Of the 144 graft losses (31.2\%) during the study period, $84(18.2 \%)$ were within the first 90 days.

Recipient Risk Factors. Allograft losses were almost threefold more common after retransplantation, and significantly more frequent when the recipient was in the UNOS 4 category (Table 2). Waiting times were longer in the successful group, presumably reflecting their more elective status, but this fell short of statistical significance $(P=.067)$.

Donor Risk Factors. Only two variables were statistically associated with outcome: donor age and donor

TABLE 2. Recipient Characteristics According to Graft Outcome

\begin{tabular}{lccc}
\hline & $\begin{array}{c}\text { Successful } \\
\text { Grafts } \\
(\mathbf{n = 3 1 8 )}\end{array}$ & $\begin{array}{c}\text { Failed } \\
\text { Grafts } \\
(\mathbf{n = 1 4 4 )}\end{array}$ & \\
\hline Age (yrs) & $51.3 \pm 0.7$ & $50.3 \pm 1$ & NS \\
Gender (M/F) & $200 / 118$ & $99 / 45$ & NS \\
Previous OLTx (\%) & 10.4 & 28.5 & $P<.00001$ \\
Diagnosis (\%): & 17.3 & 15.3 & \\
Alcoholic & 19.5 & 17.4 & \\
Cholestatic & 10.7 & 10.4 & \\
Cryptogenic & 3.1 & 9.0 & \\
Ischemic injury & 6.3 & 7.6 & \\
Malignancy & 29.6 & 28.5 & \\
Posthepatitic & 13.5 & 11.8 & \\
Other & 17.9 & 8.3 & \\
UNOS status (\%): & 45.3 & 36.8 & \\
Status 2 & 36.8 & 54.9 & $P=.0005 \dagger$ \\
Status 3 & $160 \pm 16$ & $111 \pm 17$ & $P=.067$ \\
Status 4 & 10.7 & 9.1 & NS \\
Waiting time (days) & & & \\
Positive cross-match $(\%)$ & & & \\
\hline
\end{tabular}

* No difference across diagnostic categories.

$\dagger$ Overall $P$ value for differences in UNOS status. When individual comparisons are made between groups, status 2 and 3 are significantly different from status 4 . Status 2 is not different from status 3.
TABle 3. Donor Characteristics According to Graft Outcome

\begin{tabular}{lccl}
\hline & $\begin{array}{c}\text { Successful Grafts } \\
(\mathbf{n}=\mathbf{3 1 8})\end{array}$ & $\begin{array}{c}\text { Failed Grafts } \\
(\mathbf{n}=\mathbf{1 4 4})\end{array}$ & \\
\hline Age (yrs) & $37.2 \pm 0.8$ & $43.9 \pm 1.4$ & $P<.001$ \\
Gender (M/F) & $217 / 101$ & $76 / 68$ & $P=.0014$ \\
Cause of death (\%): & & & \\
$\quad$ Anoxia & 6.6 & 9.8 & \\
Closed head injury & 9.5 & 7.7 & \\
Stroke & 37.5 & 43.4 & \\
Trauma* & 32.8 & 27.3 & \\
Other & 13.6 & 11.9 & $\mathrm{NS} \dagger$ \\
CPR (\%) & 16.9 & 17.5 & $\mathrm{NS}$ \\
Need for pressors (\%) & 40.2 & 40.1 & $\mathrm{NS}$ \\
Need for pitressin (\%) & 29.6 & 34.3 & $\mathrm{NS}$ \\
ICU LOS (days) & $3.3 \pm 0.2$ & $4.1 \pm 0.6$ & $\mathrm{NS}$ \\
Terminal AST (IU/L) & $76.6 \pm 5$ & $69.1 \pm 5$ & $\mathrm{NS}$ \\
Terminal ALT (IU/L) & $51.5 \pm 4$ & $47.2 \pm 3.6$ & $\mathrm{NS}$ \\
Ischemia time (hr) & $13.2 \pm 0.2$ & $13.5 \pm 0.3$ & $\mathrm{NS}$ \\
\hline
\end{tabular}

Abbreviations: CPR, cardiopulmonary resuscitation; ICU LOS, length of stay in intensive care unit.

* Includes multiple trauma and gunshot wounds to the head.

$\dagger$ No difference across all causes of death categories.

gender (Table 3). This already was evident within the first 3 months (data not shown).

\section{Multivariate Analyses}

Those variables found to be significant, or of borderline significance, in the univariate analysis provided the starting points for stepwise logistic regression analyses.

Graft Losses Before 90 Days. Three variables (two recipient, one donor) were identified as independent predictors of outcome: prior transplantation (odds ratio, $3.02 ; 95 \%$ CI, 1.68 to 5.45 ), UNOS 4 status (odds ratio, $1.56 ; 95 \%$ CI, 0.93 to 2.62 ), and donor age (odds ratio for an increase of 10 years, 1.34; 95\% CI, 1.14 to 1.57). A gender factor was not significant.

Graft Losses in Total Study Period. Four variables (two recipient and two donor) were identified as independent predictors of graft failure during the 1.12 to 2.6 years of follow-up: UNOS 4 status (odds ratio, 1.58; $95 \% \mathrm{CI}, 1.02$ to 2.44 ), prior transplantation (odds ratio, $2.86 ; 95 \% \mathrm{CI}, 1.65$ to 4.93 ), female donor sex (odds ratio, 1.5; $95 \%$ CI, 0.97 to 2.32 ), and donor age (odds ratio for an increase of 10 years, 1.26 ; 95\% CI, 1.1 to 1.44 ).

The Age Factor. Donors were stratified into those 60 years of age or older $(n=54)$ and those younger than this $(\mathrm{n}=408)$. Older donors $(\geq 60$ years) were more likely to be females ( 28 females, vs. 20 expected), had lower terminal transaminases, and were more likely to die of a stroke than from trauma or "other" causes (Table 4). Recipients of the old organs had a positive crossmatch with $1.9 \%$ of their donors compared with $11.3 \%$ in the recipients of younger organs $(P=.03)$ (Table 5).

Figure 1 shows the Kaplan-Meier graft survival curves. At 23 months, graft survival in the younger donor cohort was 0.71 (95\% CI, 0.66 to 0.76 ), whereas 
TABle 4. Donor Characteristics According to Donor Age

\begin{tabular}{|c|c|c|c|}
\hline & $\begin{array}{l}\text { Young Donors } \\
(<60 \text { years, } \\
n=\mathbf{4 0 8})\end{array}$ & $\begin{array}{c}\text { Old Donors } \\
(\geq 60 \text { years, } \\
\mathbf{n}=54)\end{array}$ & \\
\hline Age (yrs) & $35.9 \pm 0.7$ & $65.2 \pm 0.6$ & $P<.001$ \\
\hline Gender $(\mathrm{M} / \mathrm{F})$ & $267 / 141$ & $26 / 28$ & $P=.013$ \\
\hline \multicolumn{4}{|l|}{ Cause of death $(\%)$ : } \\
\hline Anoxia & 7.4 & 9.3 & \\
\hline Closed head injury & 9.4 & 5.6 & \\
\hline Stroke & 34.7 & 74.1 & \\
\hline Trauma* & 34.7 & 3.7 & \\
\hline Other & 13.8 & 7.4 & $P<.00001 \dagger$ \\
\hline CPR $(\%)$ & 17.9 & 11.3 & NS \\
\hline \multicolumn{4}{|l|}{ Need for pressors } \\
\hline$(\%)$ & 40.8 & 35.8 & NS \\
\hline Need for pitressin & & & \\
\hline (\%) & 32.2 & 22.6 & NS \\
\hline ICU LOS (days) & $3.6 \pm 0.3$ & $3.1 \pm 0.4$ & NS \\
\hline Terminal AST (IU/L) & $77 \pm 4.2$ & $53 \pm 5.5$ & $P=.001$ \\
\hline Terminal ALT (IU/L) & $52 \pm 3.3$ & $36 \pm 3.5$ & $P=.001$ \\
\hline Ischemia time $(\mathrm{hr})$ & $13.4 \pm 0.2$ & $12.8 \pm 0.6$ & NS \\
\hline
\end{tabular}

Abbreviations: CPR, cardiopulmonary resuscitation; ICU LOS, length of stay in intensive care unit.

* Includes multiple trauma and gun shot wounds to the head.

$\dagger$ Overall $P$ value across all cause of death categories. When individual comparisons are made between groups, stroke is significantly different from both trauma and "other."

for the older donor group it was 0.52 (95\% CI, 0.39 to $0.65)$, a difference that is highly significant $(P=.0001)$. However, this difference was only modestly reflected in the Kaplan-Meier patient survival (Fig. 2). At the 23 -month milestone, 0.78 of recipients of young livers were still alive (95\% CI, 0.74 to 0.82 ) compared with 0.71 of recipients of geriatric livers $(95 \% \mathrm{CI}, 0.59$ to 0.84) $(P=.037)$.

Figure 3 shows the predicted probability of graft fail-

TABLE 5. Recipient Characteristics According to Donor Age

\begin{tabular}{lccc}
\hline & $\begin{array}{c}\text { Young Donors } \\
(<\mathbf{6 0} \text { years, } \\
\mathbf{n = 4 0 8})\end{array}$ & $\begin{array}{c}\text { Old Donors } \\
(\geq \mathbf{6 0} \text { years, } \\
\mathbf{n}=\mathbf{5 4})\end{array}$ & \\
\hline Age (yrs) & $50.6 \pm 0.6$ & $53.8 \pm 1.4$ & $P=.065$ \\
Gender (M/F) & $262 / 146$ & $37 / 17$ & NS \\
Previous OLTx (\%) & 15.4 & 20.4 & NS \\
Diagnosis (\%): & & & \\
Alcoholic & 16.9 & 14.8 & \\
Cholestatic & 18.1 & 24.1 & \\
Cryptogenic & 10.0 & 14.8 & \\
Ischemic injury & 5.4 & 1.9 & \\
Malignancy & 6.9 & 5.6 & \\
Posthepatitic & 29.7 & 25.9 & \\
$\quad$ Other & 13.0 & 13.0 & NS \\
UNOS status (\%): & & & \\
$\quad$ Status 2 & 14.7 & 16.7 & \\
Status 3 & 42.9 & 40.7 & \\
$\quad$ Status 4 & 42.4 & 42.6 & NS \\
Waiting time (days) & $141 \pm 13$ & $174 \pm 34$ & NS \\
Positive cross-match (\%) & 11.3 & 1.9 & $P=.03$ \\
\hline
\end{tabular}

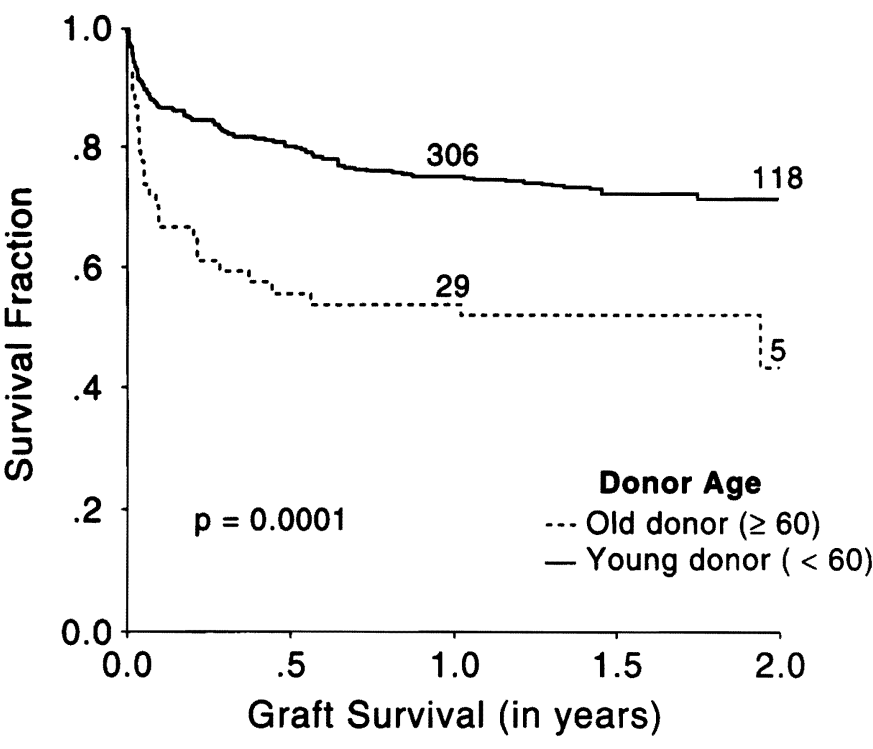

Fig. 1. Kaplan-Meier graft survival curves of "older" and "younger" donor livers. The numbers on the curves indicate the population at risk.

ure as a function of donor age, assuming that the remaining risk factors identified in this study are absent (i.e., not a retransplantation, not UNOS 4 , and male donor). Donor age was entered into this model as a smooth term, using a local regression procedure that fits a regression function to the data. This procedure is nonparametric, requiring no prior knowledge of the functional relationship between the predictors and the response variable ${ }^{35}$ thus allowing for flexible exploration of the data. The risk remained relatively uniform

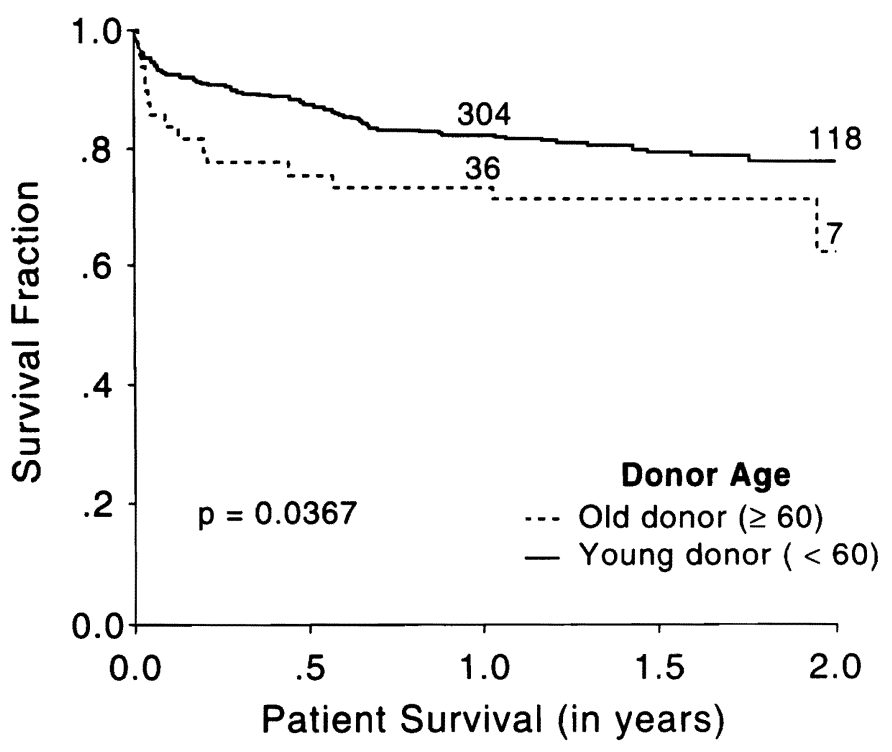

FIG. 2. Kaplan-Meier patient survival curves in recipients of "older" and "younger" donor livers. The numbers on the curves indicate the population at risk. 


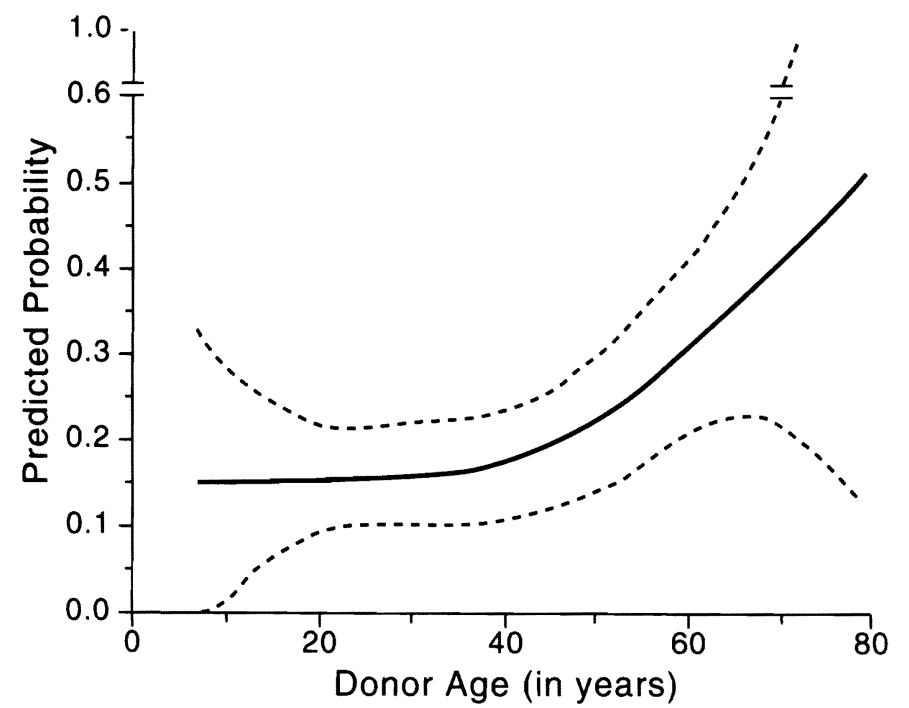

Fig. 3. Expected probability of graft failure as a function of donor age (solid line). This assumes that the organs come from male donors, the recipients are not UNOS 4 , and it is not a retransplantation. The dashed lines indicate 2 standard errors around the estimated values (thereby closely approximating a continuous $95 \%$ confidence band).

until a donor age of approximately 45 years, at which point the risk of failure began to increase significantly. This was also supported by the fact that donor age was not an independent predictor when fitting a logistic regression model on the subset of the data containing only donors 45 years of age or younger, but did come out as an independent predictor in the subset of the

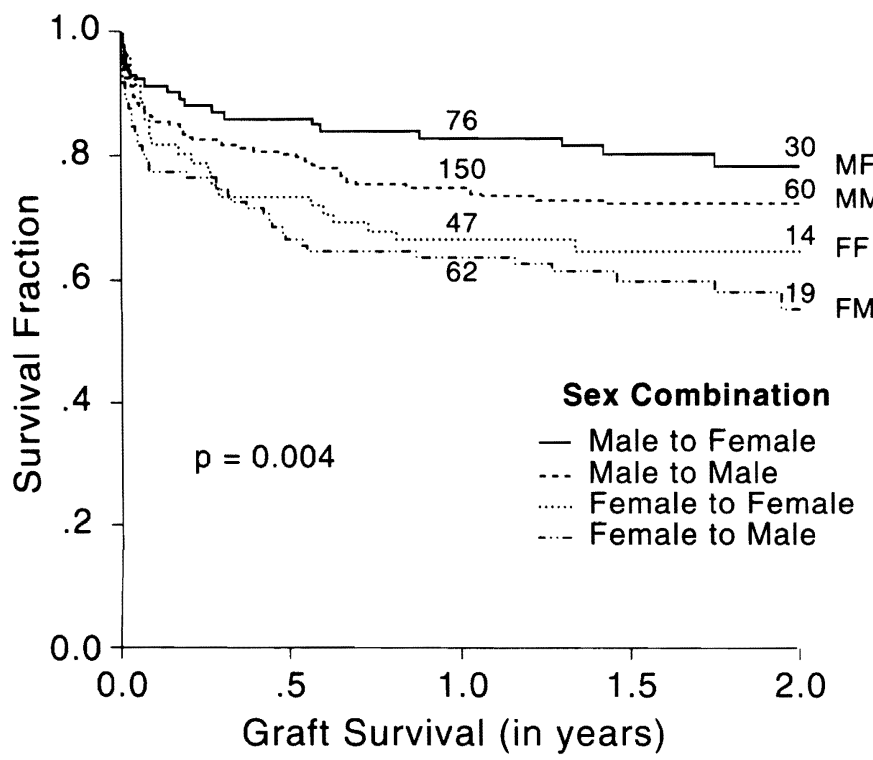

FIG. 4. Kaplan-Meier graft survival curves according to donorrecipient sex combination. The numbers on the curves indicate the population at risk. $\mathrm{MF}=$ Male to Female. $\mathrm{MM}=$ Male to Male. FF $=$ Female to Female. $\mathrm{FM}=$ Female to Male.
Table 6. Graft Survival According to Donor-Recipient Gender Combination

\begin{tabular}{lcccc}
\hline & $\begin{array}{c}\text { No. of } \\
\text { Grafts }\end{array}$ & $\begin{array}{c}\text { 2-Year Survival } \\
(\mathbf{9 5 \%} \text { CI) }\end{array}$ & $\begin{array}{c}\text { Observed } \\
\text { Failures }\end{array}$ & $\begin{array}{c}\text { Expected } \\
\text { Failures }\end{array}$ \\
\hline Female to female & 71 & $\begin{array}{c}0.64 \\
(0.54-0.77) \\
0.55\end{array}$ & 25 & 21.6 \\
Female to male & 98 & $\begin{array}{c}0.45-0.67) \\
(0.45-78\end{array}$ & 20 & 27.9 \\
Male to female & 92 & $\begin{array}{c}0.78 \\
(0.70-0.88) \\
0.72\end{array}$ & 56 & 63.8 \\
Male to male & 201 & $(0.66-0.78)$ & & \\
\hline
\end{tabular}

NOTE. $P=.004$ when comparing across groups.

data containing only donors older than 45 years (data not shown).

A limitation of this exploratory technique is that it does not readily allow calculation of pointwise standard errors, necessary for confidence interval estimation. However, this can be done indirectly, by substituting into a generalized linear model a regression spline that closely approximates the curve that was first derived from the data. Doing this, the calculated probability of graft failure for a 20-year-old donor was 0.16 (95\% CI, 0.08 to 0.24$)$, that of a 40 -year-old donor $0.18(95 \% \mathrm{CI}$, 0.11 to 0.25 ), and that of a 65-year-old donor, 0.36 (95\% CI, 0.23 to 0.49 ). Analysis of deviance of the final fitted model (using a $\chi^{2}$ test) showed that all four terms were significant: previous transplantation, $P=.000002$; UNOS $4, P=.02$; donor gender, $P=.005$; and donor age, $P=.002$.

The Gender Factor. Figure 4 shows the KaplanMeier graft survival curves with all four donor-recipient gender combinations. Graft survival was best with male donor to female recipient transplantation and worst with female to male recipient (see also Table 6). Male recipients of female livers also had reduced survival, but these trends did not reach statistical significance (Table 7), reflecting an aggressive policy of retransplantation.

The female donors were older than the male donors, received pitressin less frequently, and had a higher

Table 7. Patient Survival According to Donor-Recipient Gender Combination

\begin{tabular}{lcccc}
\hline & $\begin{array}{c}\text { No. of } \\
\text { Grafts }\end{array}$ & $\begin{array}{c}\text { 2-Year Survival } \\
(95 \% \text { CI })\end{array}$ & $\begin{array}{c}\text { Observed } \\
\text { Failures }\end{array}$ & $\begin{array}{c}\text { Expected } \\
\text { Failures }\end{array}$ \\
\hline Female to female & 62 & 0.82 & 11 & 14.4 \\
Female to male & 83 & $\begin{array}{c}(0.73-0.92) \\
0.66\end{array}$ & 26 & 17.7 \\
Male to female & 83 & $\begin{array}{c}(0.55-0.79) \\
0.82\end{array}$ & 14 & 19.9 \\
Male to male & 191 & $\begin{array}{c}(0.74-0.92) \\
0.77\end{array}$ & 44 & 43 \\
& & $(0.71-0.83)$ & & \\
\hline
\end{tabular}

NOTE. $P=.09$ when comparing across groups. 
TABLE 8. Donor Characteristics According to Donor Gender

\begin{tabular}{lccc}
\hline & $\begin{array}{c}\text { Male Donors } \\
(\mathbf{n}=\mathbf{2 9 3})\end{array}$ & $\begin{array}{c}\text { Female Donors } \\
(\mathbf{n}=\mathbf{1 6 9})\end{array}$ \\
\hline Age (yrs) & $36 \pm 0.9$ & $45 \pm 1.1$ & $P<.001$ \\
Cause of death (\%): & & & \\
$\quad$ Anoxia & 4.8 & 12.5 & \\
$\quad$ Closed head injury & 10.3 & 6.5 & \\
$\quad$ Stroke & 31.8 & 52.4 & \\
$\quad$ Trauma* & 40.4 & 14.9 & $P<.00001 \dagger$ \\
$\quad$ Other & 12.7 & 13.7 & NS \\
CPR (\%) & 15.4 & 20.1 & NS \\
Need for pressors & & & \\
$\quad(\%)$ & 40.9 & 39.0 & NS \\
Need for pitressin & & & NS \\
$\quad(\%)$ & 34.8 & 24.5 & NS \\
ICU LOS (days) & $3.5 \pm 0.2$ & $3.6 \pm 0.5$ & NS \\
Terminal AST (IU/L) & $75 \pm 4.5$ & $73 \pm 6.9$ & \\
Terminal ALT (IU/L) & $52 \pm 3.6$ & $46 \pm 5.2$ & \\
Ischemia time (hr) & $13.5 \pm 0.2$ & $13.0 \pm 3.7$ & \\
\hline
\end{tabular}

Abbreviations: CPR, cardiopulmonary resuscitation; ICU LOS, length of stay in intensive care unit.

* Includes multiple trauma and gunshot wounds to the head.

$\dagger$ Overall $P$ value across all cause of death categories. When individual comparisons are made between groups, anoxia and stroke are significantly different from trauma.

incidence of anoxia and stroke but a lower incidence of trauma as the cause of death (Table 8).

Table 9 shows the recipient characteristics according to donor gender. Among recipients of female livers, there were proportionally more UNOS 4 status than UNOS 3 recipients ( 84 status 4 vs. 72 expected, and 60 status 3 vs. 72 expected). There were also proportion-

Table 9. Recipient Characteristics According to Donor Gender

\begin{tabular}{lccc}
\hline & $\begin{array}{c}\text { Male Donors } \\
(\mathbf{n}=\mathbf{2 9 3})\end{array}$ & $\begin{array}{c}\text { Female Donors } \\
(\mathbf{n}=\mathbf{1 6 9})\end{array}$ & \\
\hline Age (yrs) & $50.5 \pm 0.7$ & $51.9 \pm 0.9$ & $\mathrm{NS}$ \\
Gender (M/F) & $201 / 92$ & $98 / 71$ & $P=.02$ \\
Previous OLTx (\%) & 14.7 & 18.3 & $\mathrm{NS}$ \\
Diagnosis (\%): & & & \\
Alcoholic & 18.4 & 13.6 & \\
Cholestatic & 20.5 & 16.0 & \\
Cryptogenic & 10.9 & 10.1 & \\
Ischemic injury & 4.1 & 6.5 & \\
Malignancy & 7.2 & 5.9 & \\
Posthepatitic & 28.0 & 31.4 & \\
Other & 10.9 & 16.6 & $\mathrm{NS}$ \\
UNOS status (\%): & & & \\
Status 2 & 15.0 & 14.8 & \\
Status 3 & 46.8 & 35.5 & \\
$\quad$ Status 4 & 38.2 & 49.7 & $P=.04 \dagger$ \\
Waiting time (days) & $142 \pm 14$ & $149 \pm 23$ & $\mathrm{NS}$ \\
Positive cross-match (\%) & 10.7 & 9.5 & $\mathrm{NS}$ \\
\hline
\end{tabular}

* Across diagnostic categories.

† Overall $P$ values for differences in UNOS status. When individual comparisons are made between groups, status 3 is significantly different from status 4 . Status 2 is not different from status 3 or 4 .
TABLE 10. Cause of Graft Failure According to Donor Age Group

\begin{tabular}{|c|c|c|c|}
\hline & $\begin{array}{c}\text { Young Donors } \\
(<60 \text { years, } n=408)\end{array}$ & $\begin{array}{c}\text { Old Donors } \\
(\geq 60 \text { years, } n=54)\end{array}$ & \\
\hline Rejection* & 7.3 & 8.0 & \\
\hline Technical & 9.2 & 8.0 & \\
\hline Ischemic injury $\dagger$ & 22.0 & 52.0 & \\
\hline Sepsis & 30.3 & 16.0 & \\
\hline Hepatitis & 5.5 & 0 & \\
\hline Cardiovascular & 8.3 & 0 & \\
\hline Other & 17.4 & 16.0 & NS $\ddagger$ \\
\hline
\end{tabular}

NOTE. Expressed as percentages.

* Includes acute and chronic rejection.

$\dagger$ Includes primary nonfunction and delayed failures because of harvesting injury.

$\ddagger$ Across all failure categories.

ally fewer female to male (98 observed vs. 109 expected) and male to female (92 observed vs. 103 expected) transplantations performed $(P<.05$ for all comparisons).

The Mantel-Haenzel test was used to control for confounding variables and provide further confirmation of the effect of donor sex on overall graft survival. Donor sex was still found to be significantly associated with outcome when controlling for prior transplant $(P$ $=.0034)$, UNOS status $(P=.0064)$, and recipient sex $(P=.0012)$.

Of 28 livers taken from females who were 60 years of age or older, $18(64.3 \%)$ failed, compared with 11 $(42.3 \%)$ of 26 when grafts were from geriatric male donors $(P=.1)$.

The causes of graft failure according to donor age are shown in Table 10, and grouped according to donor sex in Table 11. There were no gender-associated $(P=.21)$ differences. Although half of the failures in the older donor group were due to ischemic injury, this narrowly failed to reach statistical significance $(P=.07)$.

\section{DISCUSSION}

In general confirmation of the earlier study by Makowka et $a l,{ }^{11}$ donor variables such as cause of death,

TABLE 11. Cause of Graft Failure According to Donor Gender

\begin{tabular}{|c|c|c|c|}
\hline & $\begin{array}{l}\text { Male Donors } \\
\quad(n=293)\end{array}$ & $\begin{array}{c}\text { Female Donors } \\
\quad(n=169)\end{array}$ & \\
\hline Rejection* & 9.6 & 4.9 & \\
\hline Technical & 6.8 & 11.5 & \\
\hline Ischemic injury ${ }^{\dagger}$ & 31.5 & 23.0 & \\
\hline Sepsis & 27.4 & 27.9 & \\
\hline Hepatitis & 6.8 & 1.6 & \\
\hline Cardiovascular & 5.5 & 8.1 & \\
\hline Other & 12.4 & 23.0 & NSł \\
\hline
\end{tabular}

NOTE. Expressed as percentages.

* Includes acute and chronic rejection.

$\dagger$ Includes primary nonfunction and delayed failures caused by harvesting injury.

$\ddagger$ Across all failure categories. 
length of intensive care unit stay, use of pressors or pitressin, and serum transaminases were not associated with degraded graft survival. The absence of the previously reported correlation between ischemia time and outcome ${ }^{37}$ was explained by a concerted effort throughout the study period to keep cold ischemia within the "safe" window of 18 hours.

In contrast, older donor age and female gender were significant risk factors. Although it is indisputable that function of the kidneys decrease with increasing age ${ }^{38,39}$ such data on liver function and physiology are often contradictory. ${ }^{40}$ Decreases in organ weight and liver blood flow ${ }^{16,41}$ are the best documented age-related alterations, but because of the liver's great functional reserve and the ability to regenerate, these changes do not correlate well with functional deterioration when there is no concomitant pathology. ${ }^{40}$

The extent of liver vulnerability after the age of 45 years was unmasked more decisively with hepatic transplantation than by any physiologic test. The 23month graft survival using donor livers 60 years of age or older was remarkably different than with livers from donors younger than $60: 52 \%$ versus $71 \%(P=.0001)$, with patient survival of $71 \%$ versus $78 \%(P=.037)$. These results could not be attributed either to differences in the recipient populations or to less stringent selection criteria on the part of our surgeons on call who, if anything, were more cautious when considering an older donor.

The causes of death differed between the older than and younger than 60 donors, with a disproportionate number of older donors dying of strokes. However, the cause of death had no association with outcome in the total case collection (Table 3 ). The most important contributory factor to the high failure rate of the over60 livers was overrepresentation of females (28, vs. 20 expected, $P=.013$ ): the 2-year graft failure was $64.3 \%$ with these female livers, compared with $42.3 \%$ with older male organs. When all of the other significant risk factors (including donor gender) were controlled, however, a realistic impression of the age effect emerged. The rate of graft failure remained level until donor age reached 45 , doubled from age 40 to age 65 , and increased at an accelerated rate thereafter (Fig. 3 ). The dashed lines on Fig. 3 encompass a band that is 2 standard errors around the estimated values, which closely approximates a 95\% confidence band. The bands are extremely wide on both ends of age spectrum because of the sparcity of data in these regions.

The influence of donor sex on the outcome of liver transplantation has received little attention in spite of the extensive literature on renal transplantation showing inferior results with female donors ${ }^{27}$ except when there was HLA compatibility. ${ }^{27,42}$ The disarming of the adverse gender influence by histocompatibility matching in the kidney experience suggested a gender-related immunologic factor such as increased graft antigenicity not directly attributable to $\mathrm{H}-\mathrm{Y}$ minor histocompatibility antigen. This hypothesis is strengthened by our observations in liver recipients in whom the gender effect was enduring, although not identifiable within 90 days.

The addition of the liver observations to previous observations in kidney recipients is compatible with the possibility of a sex hormone (or receptor) linkage to HLA expression, while weakening alternative explanations for the gender effect on the renal recipient population. ${ }^{27}$ These alternative hypotheses included a nephron mass/functional demand disproportion caused by the systematic use of smaller female donors, and a special susceptibility of the female kidney to cyclosporine nephrotoxicity. In our liver transplant experience, also paralleling the earlier kidney studies, the double jeopardy was evident of female sex and older donor age. In a further similarity, the causes of death of the high-risk old female donors included a disproportionate number of nontraumatic cerebrovascular accidents.

Earlier reports from Pittsburgh describing a gender effect in liver transplantation ${ }^{28,29}$ were met with incredulity because confounding donor and recipient risk variables were not controlled. In the current multivariate analysis, which did not have this defect, the adverse female donor influence was pervasive, without regard for UNOS status, prior transplantation, recipient sex, a positive cytotoxic cross-match, and other factors. The lack of a deleterious effect from positive cross-match described in our earlier experience ${ }^{43}$ reflected the routine prophylactic administration perioperatively of prostaglandin-high-dose prednisone. Takaya et $\mathrm{al}^{32}$ have shown that this treatment can convert the otherwise degraded prognosis in such cases ${ }^{43}$ to that of the cross-match negative patient if the antibody titer is $\leq 1 / 512$.

It should be emphasized that the current report is only a step in the development of a risk assessment model. ${ }^{44}$ The confidence bands around the risk facing most subgroups were large. This can be improved by refining the model and by accrual and study of more cases. This will be particularly important for the currently small numbers of $\geq 60$-year livers (only $11.7 \%$ of the total), for which the less desirable female gender appeared to weigh more heavily than age. Among the over-60 donors, there is a marginally significant $(P$ $=.1$ ) difference between males and females. A strict interpretation (using the .05 criterion) would indicate no interaction. However, a trend is certainly indicated. The most elementary explanation is that the sample size is not sufficient to yield statistical significance.

Even if the conclusions from this study are confirmed (as expected), they are not apt to result in major changes in procurement or allocation policies. The disparity between livers and the demand for them is too great to arbitrarily discard part of the supply. Ethical management of the scarce organ resource requires, first, the willingness to equitably (meaning randomly) share risk among the recipient population rather than to cull donors, and, second, to aggressively resort to retransplantation in the event of primary failure. Even though the adverse effects on graft survival of female 
gender and advancing age were seemingly unmistakable in our experience, these were not reflected in a major loss of patient life because of the effective use of secondary transplantation when needed.

What to do with old female donors is the most problematic issue raised by this study. The high risk imposed by use of geriatric female livers raises the possibility that these organs should be used only under circumstances that are adjudicated on a case-by-case basis, and recorded in a separate reporting category. For example, many centers in Europe and North America exclude from recipient candidacy patients who are human immunodeficiency virus-positive, hepatitis $B$ virus carriers with evidence of DNA replication, and others with risk factors that predictably degrade patient and graft survival. Such patients would be better served by receiving old female livers than by receiving none at all.

Acknowledgment: The authors thank Dr Satish Iyengar, Associate Professor, Department of Mathematics and Statistics, University of Pittsburgh; Dr Trevor Hastie, Professor of Statistics, Department of Statistics, Stanford University; and Professor Brian D. Ripley, Professor of Applied Statistics, Department of Economics and Statistics, Oxford University, for their valuable advice during different stages of the data analysis.

\section{REFERENCES}

1. Eghtesad B, Bronsther O, Irish W, Casavilla A, Abu-Elmagd K, Van Thiel D, Tzakis A, et al. Disease gravity and urgency of need as guidelines for liver allocation. HEPATOLOGY 1994;20:56S-62S.

2. Garrison RN, Bentley FOR, Raque GHQ, Polk HC Jr, Sladek LC, Evanisko MJ, Lucas BA. There is an answer to the shortage of organ donors. Surg Gynecol Obstet 1991;173:391-396.

3. Evans RW, Orians CE, Ascher NL. The potential supply of organ donors. JAMA 1992;267:239-246.

4. Rozga J, Podesta L, LePage E, Hoffman A, Morsiani A, Sher L, Woolf GM, et al. Control of cerebral oedema by total hepatectomy and extracorporeal liver support in fulminant hepatic failure. Lancet 1993;342:898-899.

5. Strong RW, Lynch SV, Ong TH, Matsunami H, Koido Y, Balderson GA. Successful liver transplantation from a living donor to her son. N Engl J Med 1990;322:1505-1507.

6. Broelsch CE, Emond JC, Whitington PF, Thistlethwaite JR, Baker AL, Lichtor JL. Application of reduced-size liver transplants as split grafts, auxiliary orthotopic grafts, and living related segmental transplants. Ann Surg 1990;212:368-377.

7. Starzl TE, Iwatsuki S, Shaw BW Jr, Gordon RD. Orthotopic liver transplantation in 1984. Transplant Proc 1985; 17:250-258.

8. Ericzon BG, Lundgren G, Wilczek H, Groth CG. Experience with human liver grafts obtained after donor cardiac standstill. Transplant Proc 1987;19:3862-3863.

9. Yanaga K, Kakizoe S, Ikeda T, Podesta LG, Demetris AJ, Starzl TE. Procurement of liver allografts from non-heart beating donors. Transplant Proc 1990;22:275-278.

10. Starzl TE, Fung JJ, Tzakis A, Todo S, Demetris AJ, Marino IR, Doyle $\mathrm{H}$, et al. Baboon to human liver transplantation. Lancet 1993;341:65-71.

11. Makowka L, Gordon RD, Todo S, Ohkohchi N, Marsh JW, Tzakis AG, Yokoi H, et al. Analysis of donor criteria for the prediction of outcome in clinical liver transplantation. Transplant Proc 1987; 19:2378-2382.

12. Pruim J, Klompmaker IJ, Haagsma EB, Bijleveld CMA, Sloof MJH. Selection criteria for liver donation: a review. Transplant Int 1993;6:226-235.
13. Mor E, Klintmalm GB, Gonwa TA, Solomon H, Holman MJ, Gibbs JF, Watemberg I, et al. The use of marginal donors for liver transplantation: a retrospective study of 365 liver donors. Transplantation 1992;53:383-386.

14. Post J, Miller CM, Schwartz ME, Kadian M. Is it safe to liberalize donor criteria to include those over age 60 and those weighing over $90 \mathrm{Kg}$ ? Transplant Proc 1993;25:1570.

15. Morgan ZR, Feldman M. The liver, biliary tract and pancreas in the aged: an anatomic and laboratory evaluation. J Am Geriatr Soc 1957;5:59-65.

16. Popper H. Aging and the liver. In: Popper H, Schaffner F, eds. Progress in liver disease. Vol VIII. New York: Grune \& Stratton, 1985:659-683.

17. Starzl TE. The liver donor, and appendix of case material and bibliography. In: Starzl TE, ed. (with the assistance Putnam CW). Experience in hepatic transplantation. Philadelphia: Saunders, 1969:16-21, 528-545.

18. Teperman L, Podesta L, Mieles L, Starzl TE. The successful use of older donors for liver transplantation. JAMA 1989;262:2837.

19. Wall WJ, Mimeault R, Grant DR, Bloch M. The use of older donor livers for hepatic transplantation. Transplantation 1990;49:377381.

20. Wall W, Grant D, Roy A, Asfar S, Block M. Elderly liver donor. Lancet 1993;341:121.

21. Adam R, Astarcioglu I, Azoulay D, Morino M, Bao YM, Castaing $\mathrm{D}$, Bismuth $\mathrm{H}$. Age greater than 50 years is not a contraindication for liver donation. Transplant Proc 1991;23:2602-2603.

22. Grande L, Gonzalez FX, Manterola C, Garcia-Valdecasas JC, Rimola A, Fuster J, de Lacy AM, et al. Does donor age exclude liver grafting? Transplant Proc 1993;25:3151-3153.

23. Greig PD, Forster J, Superina RA, Strasberg SM, Mohamed M, Blendis LM, Taylor BR, et al. Donor-specific factors predict graft function following liver transplantation. Transplant Proc 1990;22:2072-2073.

24. Alexander JW, Vaughn WK: The use of "marginal" donors for organ transplantation: the influence of donor age on outcome. Transplantation 1991;51:135-141.

25. Buckel E, Sanchez-Urdazpal L, Steers J, Sterioff S, Wiesner $\mathrm{R}$, Krom RAF. Impaired initial function in liver grafts from donors $>50$ years of age. Transplant Proc 1993;25:15581559.

26. Ploeg RJ, D'Alessandro AM, Knechtle SJ, Stegall MD, Pirsch JD, Hoffmann RM, Sasaki T, et al. Risk factors for primary dysfunction after liver transplantation: a multivariate analysis. Transplantation 1993;55:807-813.

27. Neugarten J, Silbiger SR. The impact of gender on renal transplantation. Transplantation 1994;58:1145-1152.

28. Kahn D, Makowka L, Gavaler J, Starzl TE, Van Thiel DH. The outcome after clinical liver transplantation is influenced by the gender of the donor [Abstract]. HePatology 1988; $8: 1225$.

29. Kahn D, Gavaler JS, Makowka L, Van Thiel DH. Gender of donor influences outcome after orthotopic liver transplantation in adults. Dig Dis Sci 1993;38:1485-1488.

30. Pillay P, Van Thiel DH, Gavaler JS, Starzl TE. Donor gender does not affect liver transplantation outcome in children. Dig Dis Sci 1990;35:686-689.

31. Stratta RJ, Wood RP, Langnas AN, Duckworth RM, Shaefer MS, Marujo W, Pillen TJ, et al. Donor selection for orthotopic liver transplantation: lack of an effect of gender or cytomegalovirus (CMV) status. Transplant Proc 1990;22:410-413.

32. Takaya S, Iwaki Y, Starzl TE. Liver transplantation in positive cytotoxic crossmatch cases using FK506, high-dose steroids, and prostaglandin $\mathrm{E}_{1}$. Transplantation 1992;54:927-929.

33. Hochberg Y, Tamhane AC. Multiple comparison procedures. New York: John Wiley \& Sons; 1987:275-277.

34. Hastie TJ, Tibshirani RJ. Generalized additive models. London: Chapman \& Hall; 1990.

35. Cleveland WS, Grosse E, Shyu WM. Local regression models. In: Chambers JM, Hastie TJ, eds. Statistical models in S. London: Chapman \& Hall; 1993:309-376. 
36. Hastie TJ, Pregibon D. Generalized linear models. In: Chambers JM, Hastie TJ, eds. Statistical models in S. London: Chapman \& Hall, 1993:195-247.

37. Furukawa H, Todo S, Imventarza O, Casavilla A, Wu YM, ScottiFoglieni C, Broznick B, et al. Effect of cold ischemia time on the early outcome of human hepatic allografts preserved with UW solution. Transplantation 1991;51:1000-1004.

38. Davies DF, Shock NW. Age changes in glomerular filtration rate, effective renal plasma flow, and tubular excretory capacity in adult males. J Clin Invest 1950;29:496-507.

39. Kampmann JP, Sierbaek-Nielsen K, Kristensen M, Hansen JM: Variations in urinary creatinine and endogenous creatinine clearance due to age. Ugeskr Laeger 1971;133:2369-2372.

40. Kampmann JP, Sinding J, Moller-Jorgesen I. Effect of age on liver function. Geriatrics 1975;30:91-95.
41. Mooney H, Roberts R, Cooksley WGE, Halliday JW, Powell LW. Alterations in the liver with aging. Gastroenterol Clin North Am $1985 ; 14: 757-771$.

42. Ellison MD, Norman DJ, Breen TJ, Edwards EB, Davies DB, Daily PO. No effect of H-Y minor histocompatibility antigen in zero-mismatched living-donor renal transplants. Transplantation 1994; 58:518-520.

43. Takaya S, Duquesnoy R, Iwaki Y, Demetris J, Yagihashi A Bronsther O, Iwatsuki S, et al. Positive crossmatch in primary human liver allografts under cyclosporine or FK506 therapy. Transplant Proc 1991;23:396-399.

44. Doyle HR, Marino IR, Jabbour N, Zetti G, McMichael J, Mitchell $\mathrm{S}$, Fung J, et al. Early death or retransplantation in adults after orthotopic liver transplantation. Can outcome be predicted? Transplantation 1994;57:1028-1036. 